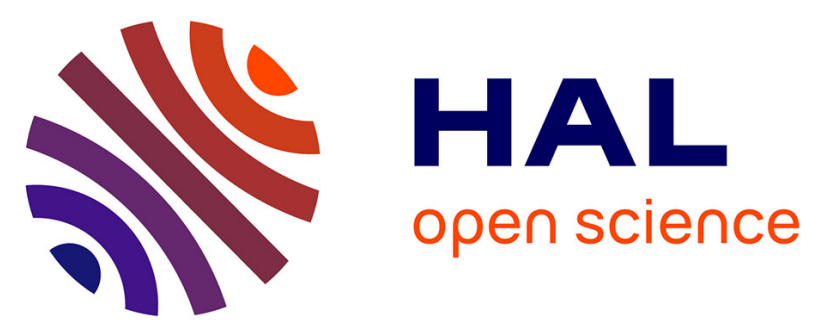

\title{
Phosphorus emitter engineering by plasma-immersion ion implantation for c-Si solar cells
}

\author{
Thomas Michel, Jerome Le Perchec, Adeline Lanterne, Rémi Monna, Frank
} Torregrosa, Laurent Roux, Mireille Commandre

\section{- To cite this version:}

Thomas Michel, Jerome Le Perchec, Adeline Lanterne, Rémi Monna, Frank Torregrosa, et al.. Phosphorus emitter engineering by plasma-immersion ion implantation for c-Si solar cells. Solar Energy Materials and Solar Cells, 2015, 133, pp.194-200. 10.1016/j.solmat.2014.11.014 . cea-02570721

\section{HAL Id: cea-02570721} https://hal-cea.archives-ouvertes.fr/cea-02570721

Submitted on 12 May 2020

HAL is a multi-disciplinary open access archive for the deposit and dissemination of scientific research documents, whether they are published or not. The documents may come from teaching and research institutions in France or abroad, or from public or private research centers.
L'archive ouverte pluridisciplinaire HAL, est destinée au dépôt et à la diffusion de documents scientifiques de niveau recherche, publiés ou non, émanant des établissements d'enseignement et de recherche français ou étrangers, des laboratoires publics ou privés. 


\title{
Phosphorus emitter engineering by plasma-immersion ion implantation for c-Si solar cells
}

\author{
Thomas Michel ${ }^{\mathrm{a}, \mathrm{b}, *}$, Jérôme Le Perchec ${ }^{c}$, Adeline Lanterne ${ }^{\mathrm{c}}$, Rémi Monna ${ }^{\mathrm{c}}$, \\ Frank Torregrosa ${ }^{a}$, Laurent Roux ${ }^{a}$, Mireille Commandré ${ }^{b}$ \\ a IBS, Rue Gaston Imbert Prolongée, Z.I. Rousset-Peynier, 13790 Peynier, France \\ ${ }^{\mathrm{b}}$ Aix-Marseille University, Ecole Centrale Marseille, CNRS, Fresnel Institute, Avenue Escadrille Normandie-Niemen, 13397 Marseille Cedex, France \\ ' CEA, LITEN, INES, 50 Avenue du Lac Léman, 73375 Le Bourget-du-Lac, France
}

\section{A R T I C L E I N F O}

\section{Article history:}

Received 24 June 2014

Received in revised form

16 October 2014

Accepted 4 November 2014

Available online 25 November 2014

Keywords:

Ion implantation

Plasma-immersion

Crystalline silicon

Solar cell

Photovoltaics

\begin{abstract}
A B S T R A C T
Ion Beam Services (IBS) has developed processes dedicated to silicon-based solar cell manufacturing using a plasma-immersion ion implantation equipment. It enables the realization of various doping profiles for phosphorus-doped emitters which fit the requirements of high-efficiency solar cells. $\mathrm{PH}_{3}$ plasma-implanted emitters are chemically, physically and electrically characterized to demonstrate their excellent quality. Those emitters are then integrated into a low cost p-type monocrystalline silicon solar cell manufacturing line from the National Solar Energy Institute (INES) in order to be compared with usual $\mathrm{POCl}_{3}$ diffusion. Starting from a basic process flow with blanket emitter and conventional full-area aluminum back-surface field, plasma-immersion implanted emitters enable to raise conversion efficiencies above $19.1 \%$. Thanks to an optimized double layer anti-reflective coating, a $19.4 \%$ champion cell has been achieved. Depending on different plasma process parameters, lightly doped emitters are then engineered aiming to study doping modulation using a dedicated laser.
\end{abstract}

(c) 2014 Elsevier B.V. All rights reserved.

\section{Introduction}

Over the past few years, high conversion efficiencies above 19\% have been achieved on p-type $156 \mathrm{~mm}$ c-Si substrates with beamline implanters dedicated to PV manufacturers [1,2]. Compared to diffusion-based doping processes, ion implantation offers a better control of the implanted dose and profile, while ensuring great uniformity and reproducibility [1]. However, the industrial integration of such a technology is rather slowed down by high implementation and running costs, since it still requires a thermal annealing step for defects healing and electrical activation of dopants [3]. Furthermore, throughputs as high as 3600 cells/h are required to fulfill the expectations of the roadmaps from the photovoltaic industry for solar cell manufacturing [4]. Plasma immersion ion implantation (PIII) reactors promise higher throughput, less investment costs and lower cost of ownership. Unlike beamline implantation, doping duration is not dependent on the implanted surface and it also offers the capability of a conformal doping, which is of particular interest for advanced textured surfaces [5] and cell architectures. IBS has developed,

\footnotetext{
* Corresponding author at: IBS, Rue Gaston Imbert Prolongée, Z.I. Rousset-Peynier, 13790 Peynier, France. Tel.: +33 442538923.

E-mail address: thomas.michel@ion-beam-services.fr (T. Michel).
}

over the last 10 years, its own plasma doping tool. PULSION ${ }^{\circledR}$ 's key feature is a proprietary remote radio frequency plasma source that enables high density plasmas with a low chamber pressure. It results in a wide process space and a specific chamber design that optimizes the doping uniformity (cf. Fig. 1) [6].

Although the first publication from IBS about PIII for crystalline silicon solar cells dates back to 2004 [7], only few papers have since been published about emitter implantation through plasma immersion [8]. Whereas IBS and INES demonstrated the strong relevance of PIII for high efficiency silicon solar cells [9], this paper studies the ability and flexibility of this immersion plasma implanter to perform emitter doping for high efficiency crystalline silicon solar cells. The influence of the emitter doping profile is observed through modeling and characterizations. Optimized emitters are then implemented within a low cost solar cell manufacturing process flow which enables a comparison with usual $\mathrm{POCl}_{3}$ diffused emitters. We then go ahead in the doping engineering by addressing the issue of emitter differential doping based on PIII.

\section{Emitter modeling and simulation}

In this part we are focused on modeling emitters and solar cells using PC1D, a software which enables modeling semiconductor 
devices and simulating their electrical behavior [10,11]. The aim of this study is to get a clear understanding of the influence of the emitter doping profile on the solar cell performances.

As an initial approach, the implanted homogeneous emitter has been modeled with complementary error functions even if we will see that the distribution of phosphorus diffused into silicon has a "kinkand-tail" shape [12]. In the complementary error function, depth and level of emitter doping are adjusted by the junction depth $\left(X_{J}[\mathrm{~nm}]\right)$ and the surface concentration $\left(C_{S}\left[\mathrm{at} / \mathrm{cm}^{3}\right]\right)$. Our calculation takes notably account of the impact of the dopant surface concentration on the front surface recombination velocity $(F S R V[\mathrm{~cm} / \mathrm{s}])$ as observed by Cuevas through the linear approximation: FSRV $=10^{-16} \mathrm{~cm}^{4} \mathrm{~s}^{-1} \times$ $C_{S}$ (if $C_{S} \geq 10^{18} \mathrm{at} / \mathrm{cm}^{3}$ ) [13]. In the same way, our calculation takes into account the degradation of the fill factor (FF) caused by increasing emitter sheet resistance. An empirical approximation is implemented within the model to make a link between the contact resistance $\left(R_{C}\right.$ in $\left.\Omega \mathrm{cm}^{2}\right)$ and the sheet resistance $\left(R_{\mathrm{sq}}\right.$ in $\left.\Omega / \mathrm{sq}\right)$ of the emitter for dopant surface concentrations between $10^{20}$ and $10^{21} \mathrm{at} / \mathrm{cm}^{3}$ : $R_{C}=-0.0275+0.000445 \mathrm{~cm}^{2} \times R_{s q} \quad\left(\right.$ if $\quad R_{s q}>64 \Omega / \mathrm{sq}$ ), otherwise $R_{C}=0.001 \Omega \mathrm{cm}^{2}[14]$.

Fig. 2 shows the variation of respectively the emitter sheet resistance and the conversion efficiency $(C E)$ according to $C_{S}$ and $X_{J}$. Through the comparison between the two diagrams, we see that the conversion efficiency is maximum for emitter sheet resistances around $60 \Omega$ /sq. Moreover, improvement of the metallization paste will decrease the contact resistance. Thus that should enable engineering of less doped (around $100 \Omega / \mathrm{sq}$ ) and

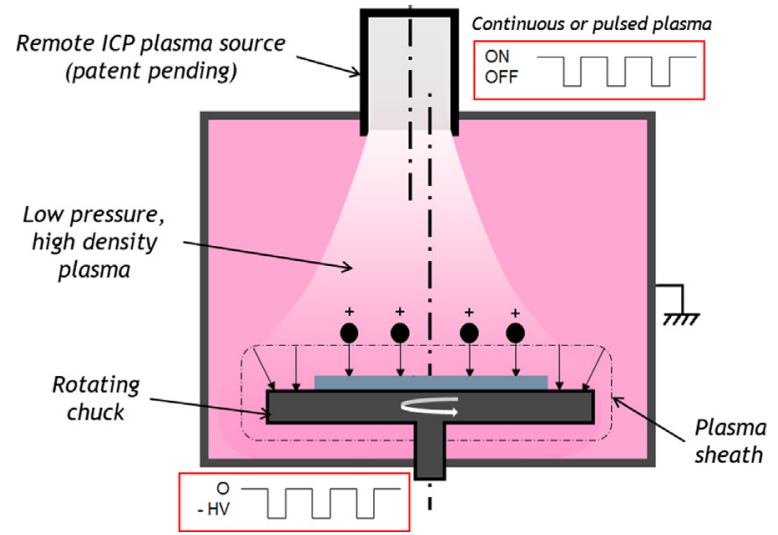

Fig. 1. Functional diagram of PULSION ${ }^{\mathbb{R}}$ ion implanter. Key features are a remote plasma source and a biased substrate being immersed in the plasma.

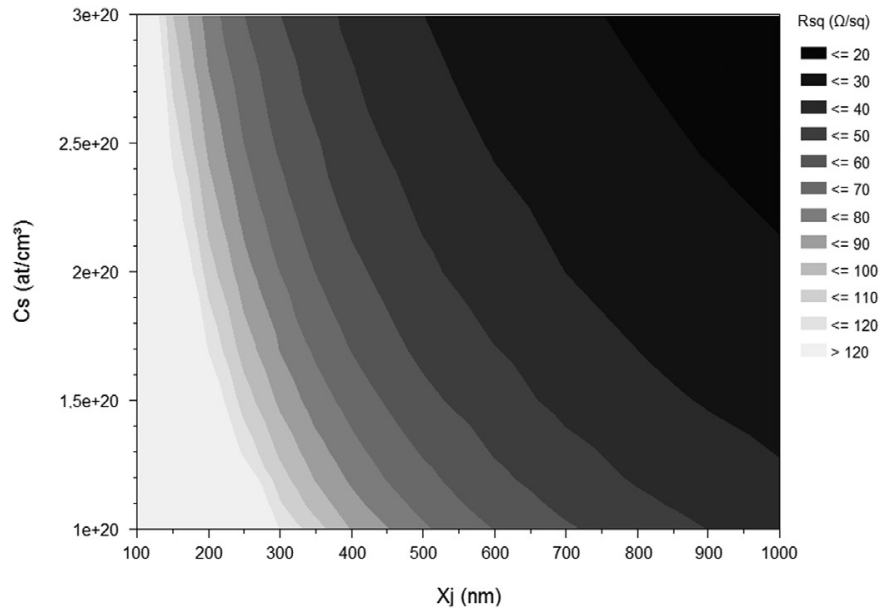

shallower emitters which enhance the blue response of the devices. In this way, pairing of implantation and thermal annealing adds some process flexibility to design tailored fit emitters.

\section{Description of experiments}

This paper highlights the process development of plasmaimmersion ion implantation for the fabrication of phosphorus homogeneous emitters. All the implantation experiments have been performed with a high productivity tool designed for the semiconductor industry. Phosphine $\left(\mathrm{PH}_{3}\right)$ has been chosen as the gas precursor required to create the phosphorus based plasma. Initially, Secondary Ion Mass Spectrometry (SIMS) analyses were performed on polished silicon wafers to understand the behavior of phosphorus and hydrogen in silicon before and after thermal annealing. Healing the defects generated by the implantation is a key target to fulfill during annealing. Thus, Transmission Electron Microscopy (TEM) has been carried out before and after oxidizing annealing to confirm the integrity of the silicon bulk crystal.

PULSION $^{\circledR}$ implantation of emitters has then been embedded in an industrial low cost process flow of monocrystalline silicon solar cells fabrication (cf. Fig. 3). INES supplied IBS with textured and cleaned p-type silicon wafers for homogeneous phosphorus implantation. The wafers were then shipped back for annealing and completion of the fabrication process. Note that the postimplantation thermal annealing includes the growth of a passivation oxide that inherently enhances the open-circuit voltage compared to the classical $\mathrm{POCl}_{3}$-based process (with single silicon nitride passivation on the front side). INES finally performed lifetime measurements and electrical characterizations of the fabricated solar cells so as to compare plasma immersion implantation to their standard $\mathrm{POCl}_{3}$ diffusion process with and without subsequent oxidation step, as highlighted by the diagram of the Fig. 3 below.

It is noteworthy that no additional cleaning has been performed between implantation and annealing steps. Indeed, neither the transport between INES and IBS nor the non-mass analyzed implantation expose the material to contamination which would significantly impact the effective lifetime of photocarriers. Contamination is regularly monitored in combination of Vapor Phase Decomposition (VPD) and Inductively Coupled Plasma Mass Spectrometry (ICP-MS). Surface concentrations of metal contaminants are usually lower than $10^{10} \mathrm{~cm}^{-2}$ and almost never exceeds the $10^{12} \mathrm{~cm}^{-2}$ threshold on $\mathrm{PH}_{3}$-implanted wafers.

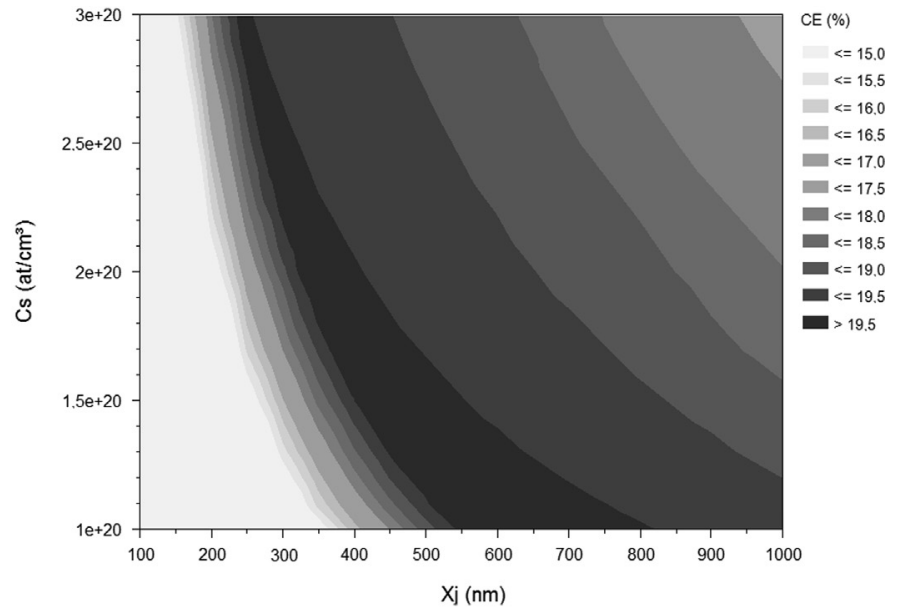

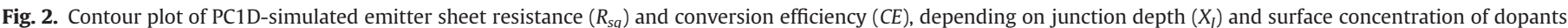
$\left(C_{S}\right)$. Simulated efficiencies are optimal when emitter sheet resistances are around $60 \Omega / \mathrm{sq}$. 


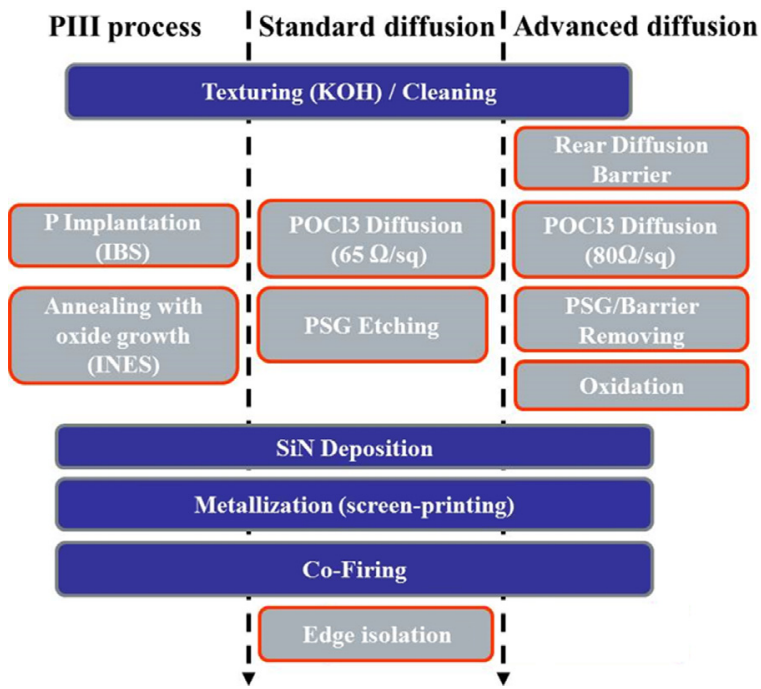

Fig. 3. Comparison of diffusion and plasma-immersion based process flows [9]. These process sequences are applied to $239 \mathrm{~cm}^{2} \mathrm{Cz}$ p-type solar cells. Compared to standard diffusion process flow, ion implantation adds an annealing process step whereas phosphosilicate glass (PSG) removal and edge isolation are suppressed. Note that the initial $80 \Omega /$ sq of the advanced diffused emitter has a final sheet resistance of around $65 \Omega$ /sq after thermal oxidation.

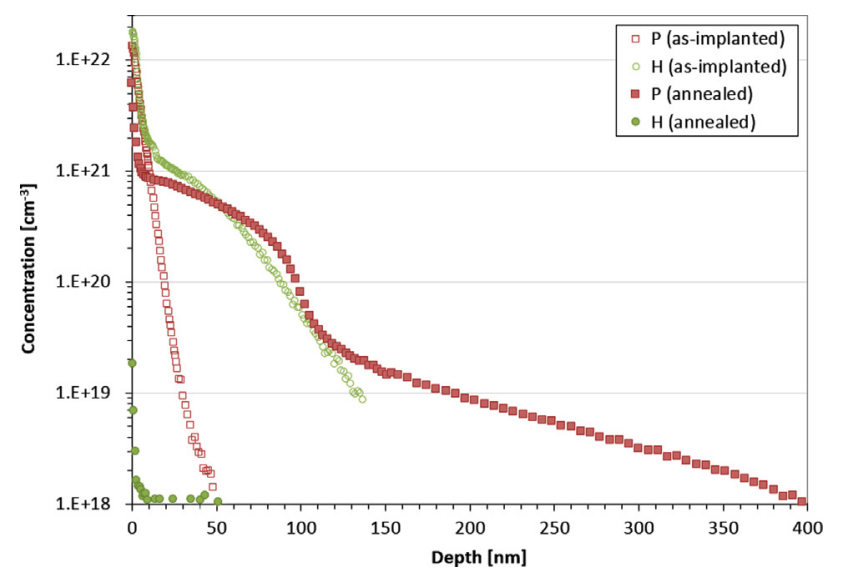

Fig. 4. Phosphorus and hydrogen SIMS profiles of a $\mathrm{PH}_{3}$-implanted emitter. Hydrogen penetration in silicon bulk is deeper than that of phosphorus. Hydrogen almost totally outdiffuses during post-implantation annealing.

\section{Phosphorus emitter implantation}

First, it has to be noticed that the $\mathrm{PH}_{3}$ gas precursor leads to the co-implantation of hydrogen through ion species such as $\mathrm{PH}_{X}{ }^{+}, \mathrm{P}_{2} \mathrm{H}_{Y}{ }^{+}$or $\mathrm{H}_{Z}{ }^{+}$. Due to the mass ratio between the two species, hydrogen is implanted deeper than phosphorus, as shown in Fig. 4. However, hydrogen is not detrimental as it almost completely outdiffuses during annealing. After furnace annealing, phosphorus SIMS profile shows a "kink-and-tail" shape for the distribution of the dopants within the silicon bulk in accordance with the vacancy-percolation model suggested by Mathiot and Pfister [12].

Left picture on Fig. 5 shows SIMS profiles of as-implanted phosphorus. Here two implantation parameters and their impact on the as-implanted phosphorus distribution have been studied: the bias voltage $(E[\mathrm{kV}])$ applied to the substrate and the setpoint dose $\left(D\left[\mathrm{at} / \mathrm{cm}^{2}\right]\right)$ which refers to the total dose of implanted ion species as measured by the equipment. Varying the bias voltage impacts the doping depth whereas the dopant surface concentration remains almost invariant. In the same way, a variation of the setpoint dose impacts the surface concentration and has almost no effect on the phosphorus implant depth.

Besides, the picture on the right (Fig. 5) demonstrates that the bias voltage - within the range of study and the given thermal budget-has no influence on the distribution of phosphorus after diffusion in the silicon bulk which is driven by the dopant surface concentration. Indeed, the high surface concentration of phosphorus acts as a tank for its diffusion into the bulk during the annealing. This diffusion mechanism may seem like a loss of freedom for emitter engineering, but it also offers the flexibility of adjusting the bias voltage as desired to fit with an optimum operating range of the implanter in terms of cost and/or throughput. Ultimately, this observation should lead to the conclusion that the bias voltage-within this range of study-has no impact on critical solar cell parameters such as emitter saturation current $\left(J_{0 e}\right)$, open-circuit voltage $\left(V_{O C}\right)$ or fill factor.

TEM analyses have been conducted to confirm the integrity of the silicon bulk after annealing. Indeed, the post-implant annealing not only aims to the dopants electrical activation, but also enables the healing of the defects caused by the ion implantation process. Fig. 6 presents TEM images on which we can clearly see about $20 \mathrm{~nm}$ of amorphized silicon bulk due to the ion bombardment. After post-implantation annealing, we see the presence of the thin silicon oxide grown during the thermal treatment.
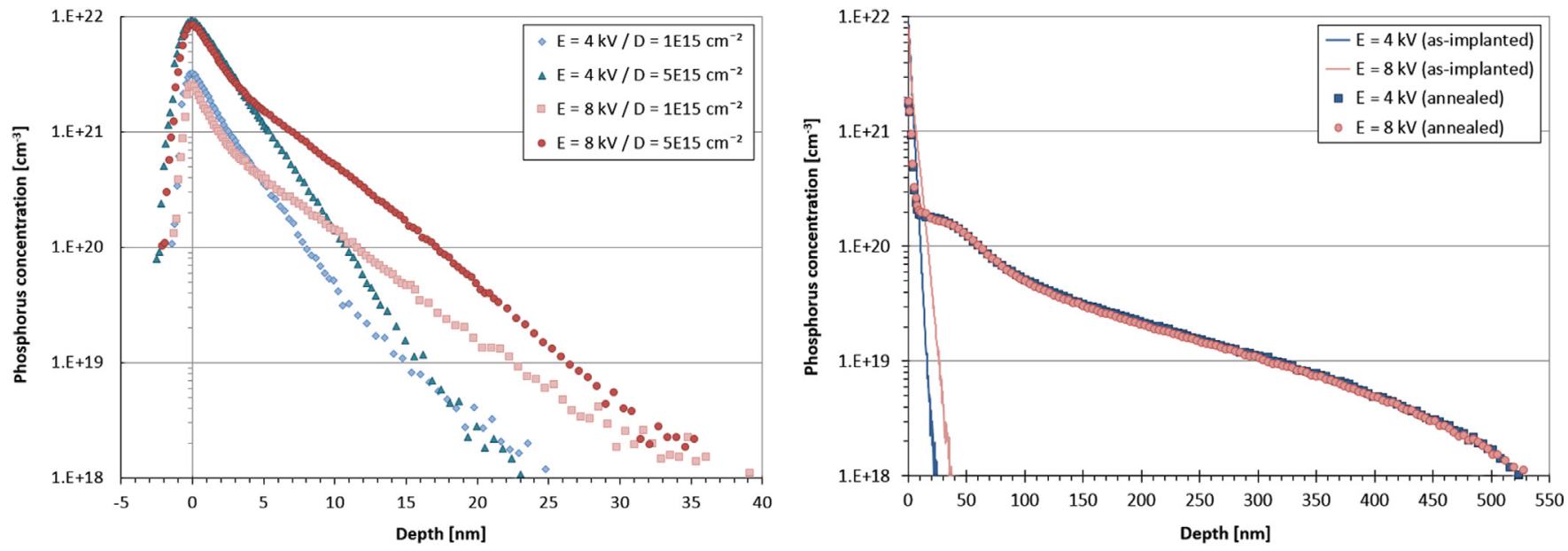

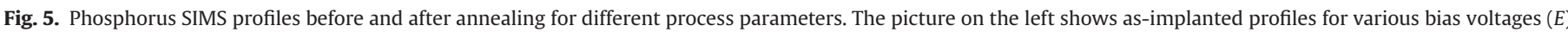

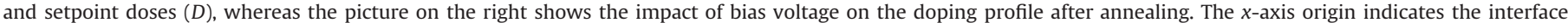
between the bulk silicon and the surface native oxide. 

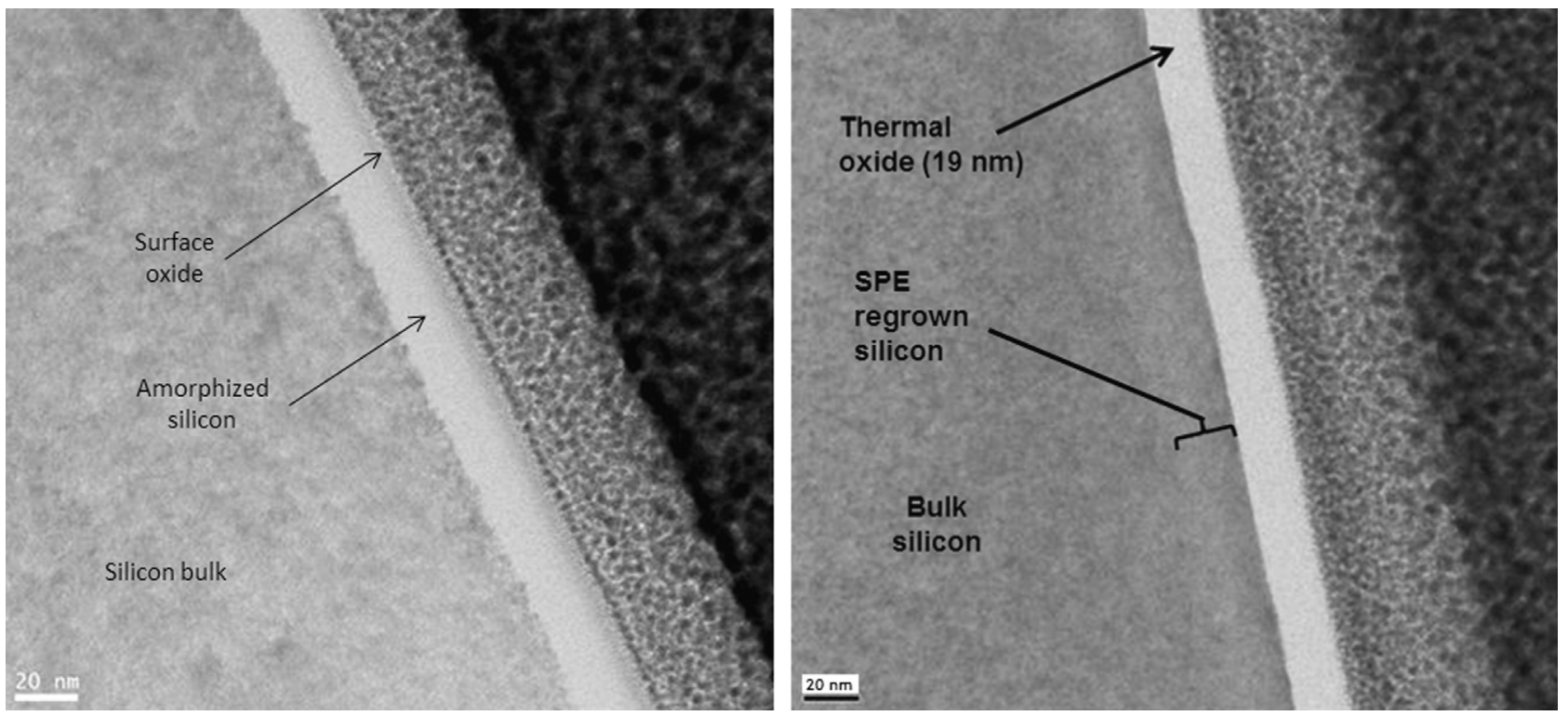

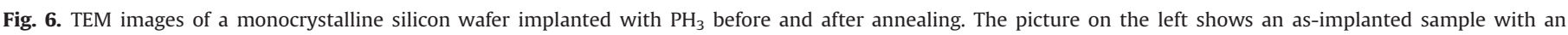

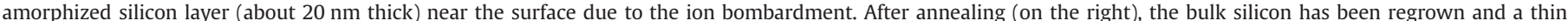
passivating oxide (less than $20 \mathrm{~nm}$ ) lays on top of the surface.

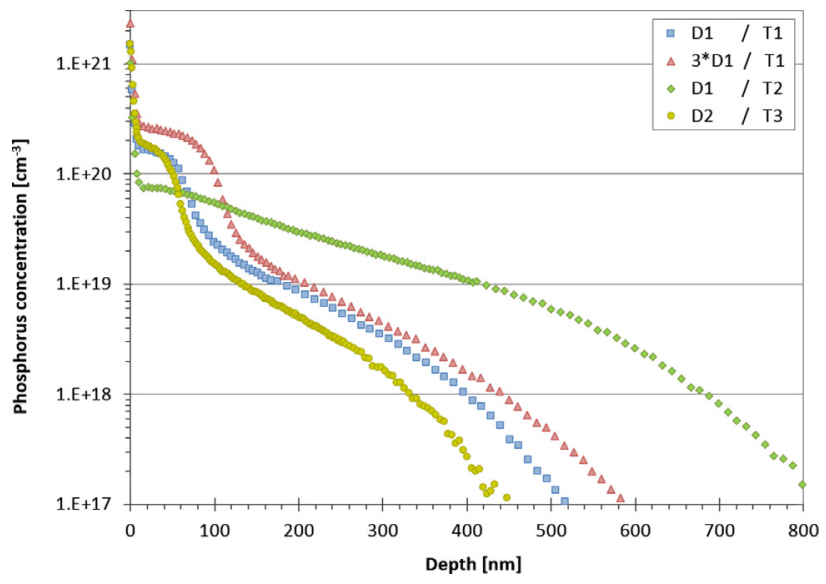

Fig. 7. Phosphorus SIMS profiles of $\mathrm{PH}_{3}$-implanted emitters with three setpoint doses of dopants $\left(D_{2}<D_{1}<3 * D_{1}\right)$ have been implanted. These polished samples have then been annealed at various temperatures $\left(T_{1}<900{ }^{\circ} \mathrm{C}, T_{2}=T_{1}+100^{\circ} \mathrm{C}\right.$, $\left.T_{3} \approx T_{1}\right)$.

Moreover a slight contrast can be observed in the bulk near the interface with the oxide: this area gives evidence of a solid-phase epitaxial recrystallization of the silicon which was amorphized by the ion bombardment. Another high resolution picture of the same wafer (not presented here) displays the atomic arrangement of the recrystallized lay and shows a clearly defined interface between the silicon and its oxide.

\section{Solar cell fabrication and characterization}

Here different $\mathrm{PH}_{3}$ dopings have been performed and characterized after annealing in order to underline the impact of the phosphorus distribution on the emitter electrical performance. Four setpoint doses ranging between $10^{15}$ and $10^{16} \mathrm{at} / \mathrm{cm}^{2}\left(D_{1}\right.$, $\left.2 * D_{1}, 3 * D_{1}, D_{2}<D_{1}\right)$ and three anneal temperatures $\left(T_{1}<900{ }^{\circ} \mathrm{C}\right.$, $T_{2}=T_{1}+100{ }^{\circ} \mathrm{C}, T_{3} \approx T_{1}$ ) have been studied. Lifetime measurement was achieved on implanted then passivated bifacial wafers. Fig. 7 shows phosphorus SIMS profiles for several implantation and
Table 1

Electrical characterizations of $\mathrm{PH}_{3}$-implanted emitters. Emitter sheet resistance $\left(R_{\mathrm{sq}}\right)$, implied open-circuit voltage $\left(i V_{O C}\right)$ and emitter saturation current $\left(J_{0 e}\right)$ have been measured on polished samples, for various combinations of setpoint doses of dopants $(D)$ and anneal temperatures $(T)$.

\begin{tabular}{lllll}
\hline $\begin{array}{l}\text { Setpoint } \\
\text { dose }\end{array}$ & $\begin{array}{l}\text { Anneal } \\
\text { temperature }\end{array}$ & $\begin{array}{l}\text { Average } R_{s q} \text { on } \\
\text { 156PSQ }[\Omega / \mathrm{sq}]\end{array}$ & $\begin{array}{l}i V_{O C} \text { (after } \\
\text { firing) }[\mathrm{mV}]\end{array}$ & $\begin{array}{l}J_{0 e} \text { (after firing) } \\
{\left[\mathrm{fA} / \mathrm{cm}^{2}\right]}\end{array}$ \\
\hline$D_{1}$ & $T_{1}$ & 53 & 641 & 155 \\
$2 * D_{1}$ & $T_{1}$ & 49 & 642 & 231 \\
$3 * D_{1}$ & $T_{1}$ & 38 & 635 & 299 \\
$D_{1}$ & $T_{2}=T_{1}+100{ }^{\circ} \mathrm{C}$ & 44 & 597 & \#N/A \\
$D_{2}$ & $T_{3} \approx T_{1}$ & 68 & 646 & 134 \\
\hline
\end{tabular}

anneal conditions, whereas Table 1 recaps results of the related electrical characterizations.

By minimizing phosphorus concentration near the surface, these doping profiles avoid electrically inactive dopants which are highly detrimental to emitter quality. In accordance with the PC1D simulations, we observe on Table 1 that higher is the setpoint dose, higher is the emitter saturation current (because of increasing Auger recombination) and thus lower is the implied open-circuit voltage $\left(i V_{O C}\right)$.

Being annealed at high temperature, the optimized emitter $\left(D_{1}\right.$, $T_{2}$ ) presents improved $J_{0 e}$ and $i V_{O C}$ before firing thanks to a lower surface concentration of dopants. However, we observe a deteriorated $i V_{O C}$ after simulating the firing process. A Light Beam Induced Current (LBIC) lifetime measurement emphasized swirl crystal defects which could have been formed during the high temperature annealing.

Table 2 compiles results from illuminated (AM1.5) I-V measurement of cells with those $\mathrm{PH}_{3}$-implanted emitters. Thanks to a lower concentration of dopants, cells with emitter $\left(D_{1}, T_{1}\right)$ show higher short-circuit current $\left(J_{S C}\right)$ and $V_{O C}$ than those with emitter $\left(3 * D_{1}, T_{1}\right)$ in accordance with our PC1D simulations. However these cells are less efficient because of a lower fill factor. That's why setpoint dose and anneal temperature have been optimized $\left(D_{2}, T_{3}\right)$ to enhance both $J_{S C}$ and $V_{O C}$, while the metallization step has also been improved to avoid the $F F$ deterioration caused by a lower emitter doping level. A conversion efficiency of $19.15 \%$ has been obtained with emitter $\left(D_{2}, T_{3}\right)$ and has been independently 
Table 2

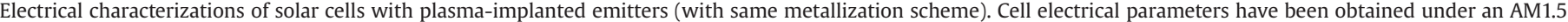
illumination ( 1 sun)

\begin{tabular}{|c|c|c|c|c|c|c|}
\hline Setpoint dose & Anneal temperature & Average $R s q[\Omega / s q]$ & Average $J_{S C}\left[\mathrm{~mA} / \mathrm{cm}^{2}\right]$ & Average $V_{O C}[\mathrm{mV}]$ & Average $F F[\%]$ & Average $C E[\%]$ \\
\hline $\mathrm{POCl}_{3}$ diffusion without oxidation & $\# \mathrm{~N} / \mathrm{A}$ & 65 & 36.9 & 635 & 79.9 & 18.7 \\
\hline $\mathrm{POCl}_{3}$ diffusion with oxidation & $\# \mathrm{~N} / \mathrm{A}$ & 65 & 37.1 & 644 & 80.1 & 19.15 \\
\hline$D_{1}$ & $T_{1}$ & 53 & 37.2 & 637.6 & 78.0 & 18.5 \\
\hline $3 * D_{1}$ & $T_{1}$ & 38 & 36.3 & 634.3 & 80.9 & 18.7 \\
\hline$D_{2}$ & $T_{3} \approx T_{1}$ & 67 & 37.5 & 645.4 & 79.1 & 19.14 \\
\hline
\end{tabular}

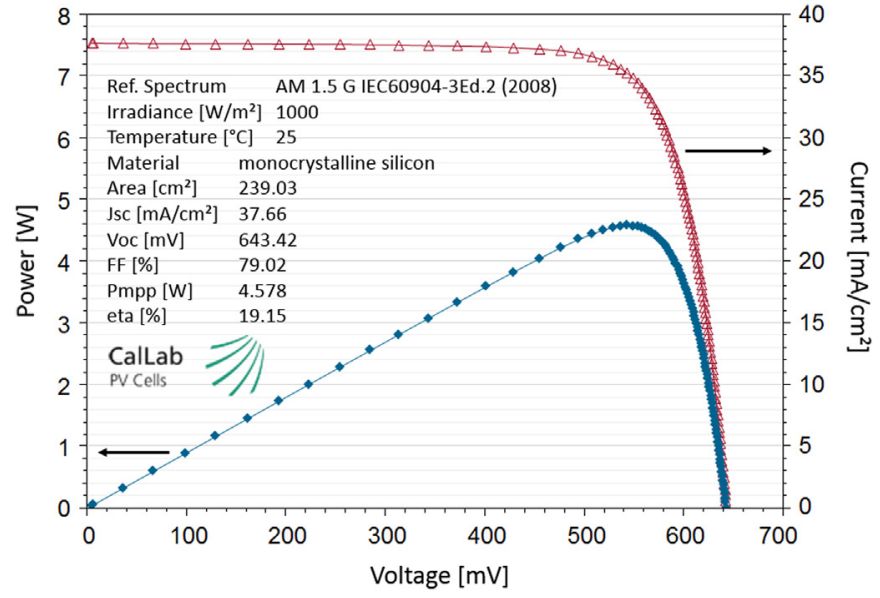

Fig. 8. $I-V$ curves and electrical results for a $239 \mathrm{~cm}^{2}$ textured $\mathrm{c}-\mathrm{Si}$ wafer with emitter $\left(D_{2}, T_{3}\right)$ following the PII process flow on Fig. 3. These results have been certified by the Fraunhofer ISE CalLab.

confirmed by the Fraunhofer ISE CalLab (see Fig. 8). We thus got a gain of more than $0.4 \%$ absolute compared to $\mathrm{POCl}_{3}$-based reference cells from INES. Finally, by resorting to an optimized nitride double layer anti-reflective coating, we obtained a $19.4 \%$ champion cell, and an average above $19.3 \%$ over 7 cells with almost no dispersion.

In order to accurately highlight the benefits of ion implanted emitters, PIII process sequence is also compared to lighter $\mathrm{POCl}_{3}$ diffusion ( $80 \Omega$ /sq recipe, see Fig. 3) followed by oxidation that significantly enhances the n-type emitter quality. Average conversion efficiencies of $19.15 \%$ have been achieved with 11 cells with a $19.28 \%$ champion cell.

Despite similar performance, we estimate that emitter engineering by ion implantation could bring an efficiency absolute gain up to $0.2 \%$ by comparison to $\mathrm{POCl}_{3}$ diffusion with oxidation. However, the main advantage of PIII sequence certainly is that it requires two fewer process steps than advanced diffusion with oxidation.

\section{Lightly doped emitters}

There are at least two ways to continuously control the sheet resistance of implanted n-type emitters: the implantation dose and the activation annealing. Classically, the sheet resistance decreases when the dose and/or the annealing temperature increases. However, unlike beamline implanters, there is no discrimination between different ionic species $\left(P_{X} \mathrm{H}_{Y}{ }^{+}, \mathrm{H}_{Z}{ }^{+}\right)$in the plasma-immersion chamber. Thus, the phosphorous dose which is effectively implanted also depends on plasma and process conditions such as the chamber pressure $(P)$ and the radio frequency power $(R F)$ related to the induction plasma technology. Indeed, varying the chamber pressure through the incoming $\mathrm{PH}_{3}$ gas flow impacts the residence time of gas molecules within the
Table 3

Electrical parameters and cell performances on $239 \mathrm{~cm}^{2}$ textured c-Si wafers, for different process conditions. Cell electrical parameters have been obtained under an AM1.5 illumination (1 sun).

\begin{tabular}{llll}
\hline Process conditions: $R F_{0}<R F_{1}$ and $P_{1}<P_{0}$ & $R F_{0} / P_{0}$ & $R F_{O} / P_{1}$ & $R F_{1} / P_{0}$ \\
\hline Sheet resistance $[\Omega / \mathrm{sq}]$ & 70.5 & 117.7 & 90.5 \\
$i V_{O C}$ before firing [mV] & 641 & 656 & 653 \\
$i V_{O C}$ after firing [mV] & 645 & 620 & 637 \\
$J_{0 e}$ after firing [fA/cm²] & 141 & 77 & 43 \\
$J_{S C}\left[\mathrm{~mA} / \mathrm{cm}^{2}\right]$ & 37.5 & 36.8 & 37.7 \\
$V_{O C}[\mathrm{mV}]$ & 645.2 & 641.0 & 647.9 \\
$F F[\%]$ & 79.1 & 51.9 & 73.0 \\
Pseudo-FF [\%] & 83.0 & 77.1 & 81.9 \\
Efficiency [\%] & 19.14 & 12.25 & 17.90 \\
\hline
\end{tabular}

source as well as the electron temperature of the plasma [15]. This is the point we address in this section: studying plasma/process conditions to achieve lightly doped emitters, which can be a starting point for engineering selective emitters.

After cleaning, textured $\mathrm{Cz}$-silicon wafers of resistivity between 1 and $3 \Omega \mathrm{cm}$ were homogeneously implanted to realize solar cells according to the industrial process already developed by INES in previous works (see Fig. 3). Concerning the emitter implantation step, two chamber pressures $\left(P_{1}<P_{0}\right.$, ranging between $10^{-4}$ and $10^{-2}$ mbar) and r.f. powers $\left(R F_{0}<R F_{1}\right)$ have been studied while bias voltage, setpoint dose and annealing parameters were kept unchanged. Some wafers were double-side implanted and passivated after annealing so as to evaluate implied open-circuit voltages and emitter saturation currents, whereas polished wafers were also implanted for SIMS measurement of the emitter doping profile.

Table 3 provides electrical results for the different process parameters: $\left(R F_{0}, P_{0}\right)$ which are the standard conditions, $\left(R F_{0}, P_{1}\right)$ and $\left(R F_{1}, P_{0}\right)$. Following the explanation reported in the previous section, we observe a variation of the emitter sheet resistance which can be related to different ion compositions of the plasma. First, increasing the r.f. power from $R F_{0}$ to $R F_{1}$ leads to a higher emitter sheet resistance. SIMS profiles in Fig. 9 show that this r.f. power increase results in a lower implanted dose of phosphorus which could be explained by a predominance of $\mathrm{P}_{1} \mathrm{H}_{X}{ }^{+}$ions over $\mathrm{P}_{2} \mathrm{H}_{Y}{ }^{+}$ions in the plasma at higher r.f. powers. On the other hand, decreasing the chamber pressure leads to a higher emitter sheet resistance. Lowering the injected gas flow increases the residence time of $\mathrm{PH}_{3}$ molecules within the source. This results in an increased dissociation of phosphine molecules and thus in a higher proportion of hydrogen species into the plasma. That is why we observe a lower implanted dose of phosphorus regarding to a constant total ion dose.

As shown in Table 3 and despite showing good $i V_{O C}$ after annealing, lightly doped emitters $\left(R F_{0}, P_{1}\right)$ and $\left(R F_{1}, P_{0}\right)$ are less robust after firing (possible sensitivity to surface depletion). As these lightly doped process conditions lead to high proportions of implanted hydrogen regarding to the total implanted dose, we might also have concerns about possible formation of voids or nanocavities after outdiffusion of large amounts of hydrogen gas 


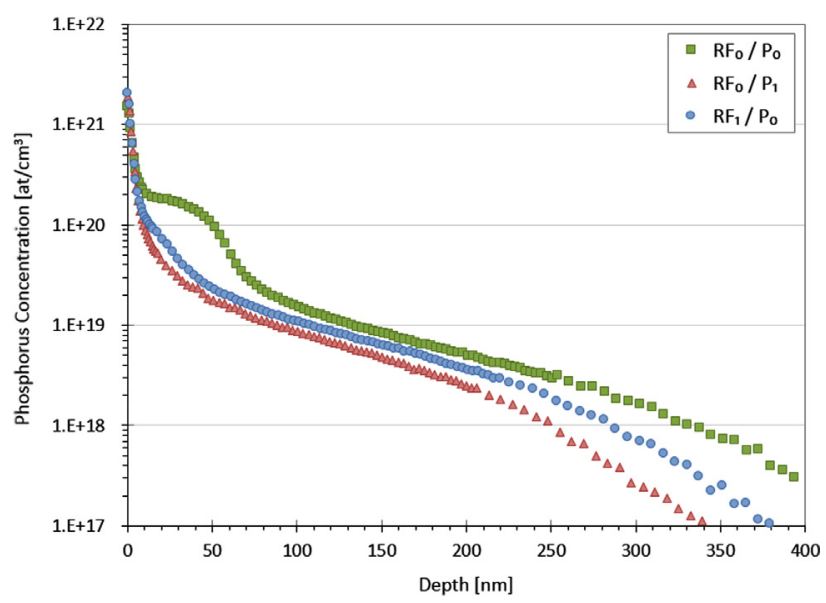

Fig. 9. Phosphorus SIMS profiles after annealing on $100 \mathrm{~mm}$ polished $\mathrm{CZ}-\mathrm{Si}$ wafers, for different r.f. power and chamber pressure conditions $\left(P_{1}<P_{0}, R F_{0}<R F_{1}\right)$. The $x$-axis origin indicates the interface between the bulk silicon and the surface oxide.

[16]. However hydrogen implantation doses that are required to form cavities are about a decade higher than those co-implanted with phosphorus in this study.

Besides these severe voltage drops after firing, the fill factors also dramatically fall due to strong series resistances and/or emitter shunting during the co-firing. This is well consistent with the SIMS profiles displayed in Fig. 9 (obtained on polished wafers with same implantation dose as textured wafers). Thus, the nonstandard conditions presented here are not relevant to achieve efficient homogeneous emitters. Obviously, another way to reduce the effective doping would be to directly decrease the total implantation dose instead of changing r.f. power and pressure parameters.

\section{Laser doping modulation}

Although $70 \Omega$ /sq homogeneous implanted emitters are already of high quality, it is interesting to study the possibility to make differential doping profiles to fabricate a selective emitter starting from light blanket implantations, that is to say without using shadow masks for instance by using the specific as-implanted profile of the PIII technology. In this framework, INES suggests to exploit a specific nanosecond green laser to slightly modulate the sheet resistance of the emitter after thermal annealing [17], with or without oxidation. Such a technique is an interesting and flexible alternative to selective implantation through shadow masking [1]. It has also been tested on PIII emitters by another research team but no cell results were given [18].

In the previous section, the process conditions around $\left(R F_{1}, P_{0}\right)$ could be quite relevant to realize the initial lightly doped emitter ( $90 \Omega /$ sq). Fig. 10 shows local modulation of the sheet resistance by laser control for two lightly doped n-type emitters presenting the same initial sheet resistance, with and without oxide passivation. Laser doping of a diffusion-based emitter $\left(\mathrm{POCl}_{3}\right)$ reference is also displayed for comparison. We note a significant decrease of the sheet resistance with increasing laser fluences. Starting from an initial $90 \Omega$ /sq (after thermal annealing), we can obtain nearly $65 \Omega /$ sq for PIII emitters, and less than $40 \Omega$ /sq for the $\mathrm{POCl}_{3}$ case in which the emitter still exhibits the PSG layer on top. It is worth noting that the laser flows used here are relatively low and thus do not deteriorate the surface state. We also note that the sheet resistance is lower without oxide layer, as the superficial oxidation consumes some phosphorus atoms that are not totally activated afterwards.

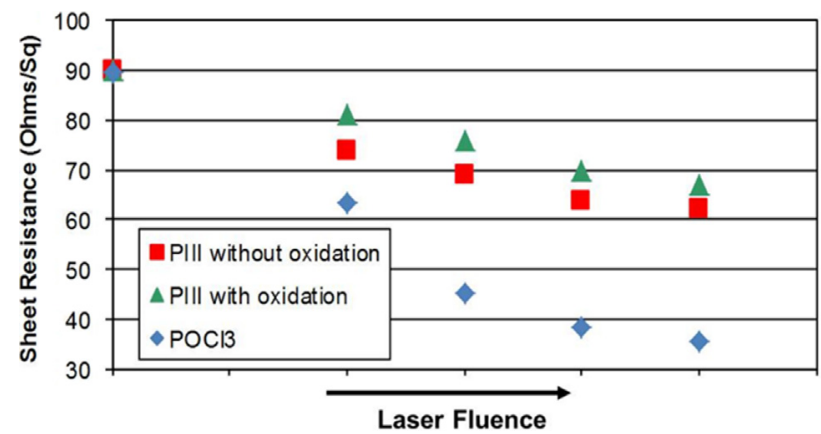

Fig. 10. Local modulation of the sheet resistance by laser control for two lightly doped n-type emitters. Laser doping of a light diffusion-based emitter $\left(\mathrm{POCl}_{3}\right)$ reference is also displayed for comparison.

Unlike diffusion-based processes where the phosphosilicate glass can be used as an important doping source when the laser scans the surface, there is no such doping source at the emitter surface. As a consequence, this drive-in allows minimizing the risks to shunt the light emitter through the metallizations' firing but should not be too pronounced in order to keep a sufficiently high surface concentration.

However, this significant sheet resistance decrease cannot just be explained by a drive-in mechanism. Additional dopant activation could come from phosphorus trapped inside the oxide or within the first nanometers of silicon bulk (phosphorus pile-up due to segregation at the interface $\mathrm{Si}-\mathrm{SiO}_{2}$ [19] as shown on Fig. 9). By this way, further experiments (SIMS profiles and contact resistance measurement) should be performed to check whether high laser fluences can lead to significant sheet resistance decreases without weakening contact resistance for future metallization.

\section{Conclusion and perspectives}

This work has led to the development of processes dedicated to silicon-based solar cell manufacturing using a plasma-immersion ion implantation equipment. We showed that PIII enables the realization of various doping profiles for phosphorus-doped emitters which fit the requirements for high-efficiency solar cells. Emitters thus fabricated were chemically, physically and electrically characterized to demonstrate their excellent quality. Integrated into a low cost solar cell manufacturing line from INES on monocrystalline silicon, those emitters enable to achieve conversion efficiencies up to $19.4 \%$ with a nitride double layer antireflective coating.

We also illustrated some non-standard conditions which give lightly doped emitters that could be used to perform selective emitters. By exploiting a drive-in mechanism, a laser scan allows a significant decrease of the local sheet resistance. This could be a practical and promising alternative to masking techniques for differential doping engineering.

Thanks to this work, the strength and potential of PIII for photovoltaic applications have been proven and this has convinced IBS to design and fabricate an equipment dedicated to solar cell manufacturing.

\section{Acknowledgments}

This research was conducted under the CIFRE process initiated by the French Ministry of Higher Education and Research. These results have been partly achieved within the PULSARCELL project supported by the French FUI. 


\section{References}

[1] A. Gupta, R.J. Low, N. Bateman, D. Ramappa, H.J. Gossman, Q. Zhai, P. Sullivan, W. Skinner, C. Dubé, B. Tsefrekas, J. Mullin, High efficiency selective emitter cells using in-situ patterned ion implantation, in: Proceedings of the 25th EU PVSEC, 2010, pp. 1158-1162.

[2] A. Rohatgi, D.L. Meier, B. McPherson, Y.W. Ok, A.D. Upadhyaya, J.H. Lai, F. Zimbardi, High-throughput ion-implantation for low-cost high-efficiency silicon solar cells, Energy Proc. 15 (2012) 10-19.

[3] J.D. Plummer, M.D. Deal, P.B. Griffin, Silicon VLSI Technology: Fundamentals, Practice and Modeling, Prentice Hall, Upper Saddle River, NJ, 2000 (Implantation-Chapter 8).

[4] SEMI PV Group, International Technology Roadmap for Photovoltaic, 5th Edition, 2014, 〈http://www.itrpv.net/Reports/Downloads/〉 (last accessed: June 2014).

[5] T. Sarnet, T. Derrien, R. Torres, P. Delaporte, F. Torregrosa, M.J. Sher, Y.T. Lin, B. Franta, G. Deng, E. Mazur, Black silicon for photovoltaic cells: towards highefficiency silicon solar cells, in: Proceedings of the 28th EU PVSEC, 2013, pp. $1882-1886$.

[6] S.B. Felch, F. Torregrosa, H. Etienne, Y. Spiegel, L. Roux, D. Turnbaugh, PULSION ${ }^{\circledR}$ HP: Tunable, high productivity plasma doping, AIP Conf. Proc. 1321 (2010) 333-336.

[7] F. Torregrosa, C. Laviron, H. Faik, D. Barakel, F. Milesi, S. Beccaccia, Realization of ultra shallow junctions by PIII: application to solar cells, Surf. Coat. Technol. 186 (2004) 93-98.

[8] T. Janssens, N.E. Posthuma, E. van Kerschaver, K. Baert, P. Choulat, J.L. Everaert, J. Goosens, W. Vandervorst, J. Poortmans, Advanced phosphorus emitters for high efficiency si solar cells. in: Proceedings of the 34th IEEE PVSC, 2009, pp. $878-882$.

[9] J. Le Perchec, A. Lanterne, T. Michel, S. Gall, R. Monna, F. Torregrosa, L. Roux, $19.3 \%$ efficiency on p-type silicon solar cells by PULSION ${ }^{\circledR}$ plasma-immersion implantation, Energy Proc. 33 (2013) 18-23.
[10] University of New South Wales, PC1D, 〈http://www.engineering.unsw.edu.au/ energy-engineering/pc1d-software-for-modelling-a-solar-cell/> (last accessed: June 2014).

[11] P.A. Basore, Numerical modeling of textured silicon solar cells using PC-1D, IEEE Trans. Electron. Dev, 37 (1990) 337-343.

[12] D. Mathiot, J.C. Pfister, Dopant diffusion in silicon: a consistent view involving nonequilibrium defects, J. Appl. Phys. 55 (1984) 3518-3530.

[13] A. Cuevas, P.A. Basore, G. Giroult-Matlakowski, C. Dubois, Surface recombination velocity of highly doped n-Type silicon, J. Appl. Phys. 80 (1996) 3370-3375.

[14] D. Grote, M. Hermle, E.A. Wotke, U. Belledin, M. Hörteis, M. Spitz M. Kasemann, S. Rein, D. Biro, W. Warta, Analyzing the effects of laterally varying emitter sheet resistance in combination with contact resistance, in: Proceedings of the 23rd EU PVSEC, 2008, pp. 278-282.

[15] A. Anders, J. Pelletier, D.M. Goebel, B.P. Wood, I.G. Brown, W. Ensinger, M. Tuszewski, Plasma Sources, in: A. Anders (Ed.), Handbook of Plasma Immersion Ion Implantation and Deposition, John Wiley and Sons, 2000, pp. 406-408.

[16] A. Kouadri Boudjelthia, G. Regula, E. Ntsoenzok, M. Canino, R. Benoit, F. Torregrosa, M. Allegrezza, Trapping of metallic impurities in multicrystalline silicon wafers, in: Proceedings of the 28th EU PVSEC, 2013, pp. 1414-1417.

[17] A. Lanterne, S. Manuel, B. Paviet-Salomon, S. Gall, A. Tauzin, Implanted selective emitter solar cell by laser thermal annealing, AIP Conf. Proc. 1496 (2012) 131-134.

[18] A. Lawerenz, K. Neckermann, G. Andrä, Plasma immersion ion implantation as an alternative to diffusion and beam-line implantation for creating phosphorus doped emitters and selective emitters, in: Proceedings of the 27th EU PVSEC, 2012, pp. 1553-1557.

[19] J.D. Plummer, M.D. Deal, P.B. Griffin, Silicon VLSI Technology: Fundamentals, Practice and Modeling, Prentice Hall, Upper Saddle River, NJ, 2000 (DiffusionChapter 7). 